\title{
Detection of Cryptosporidium species among Malnourished Children in and around Chennai, Tamil Nadu, Southern India
}

\author{
G.S. Chamundeeswari*, R. Raghuraman and M. Raman \\ Department of Microbiology, Stanley Medical College, Chennai 600 001, Tamilnadu, India \\ *Corresponding author
}

\section{A B S T R A C T}

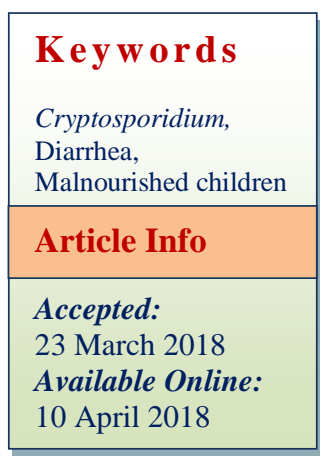

Aim of the study is to detect Cryptosporidium, a newly emerging parasite in malnourished children with and without diarrhea, using conventional methods and special staining techniques. A total of 727 children comprised of 497 malnourished and 230 normal children having with and without diarrhoea. Two consecutive samples were collected from each individual and one preserved using 10\% formalin. Examination of helminthes and protozoan in the stool samples were done by direct wet mount method and by formalin ether sedimentation method. Smear made from the deposit were stained using modified Kinyoun's Acid Fast stain for Cryptosporidium. The size of the cryptosporidium was measured using micrometer. Among 727 samples, 12/727 (1.65\%) were found to be positive for Cryptosporidium. All the individuals were found to have profuse watery diarrhea. Other enteric parasites such as Giardia, Hookworm, Entamoeba histolytica were also detected. Children within the age group of $>5$ year were found to be more vulnerable for Cryptosporidial infection.

\section{Introduction}

Cryptosporidium sp. is a coccidian parasite recognized as an obligatory enteric protozoan commonly inhabiting the intestinal mucosa (Current and Garcia, 1991). Its transmission has been implicated in multiple pathways such as animal to human, water contamination and person-to-person contact.

Unlike immunocompetent adults, in whom cryptosporidiosis is usually self-limited, the infection in malnourished children and immunocompromised individuals suffering from AIDS and cancer is much more severe and may often be life-threatening. People with
AIDS are susceptible to a devastating form of cryptosporidiosis manifested by chronic voluminous diarrhoea, usually unremitting form that is intractable to therapy (Hunter et al., 2002). Earlier, documented evidence on the prevalence of Cryptosporidium sp. in paediatric diarrhoea was found to be in the range of 1.1 to $13.1 \%$ from different parts of India based on the microscopic detection of oocysts in faecal specimen (Subramanyam et al., 1989; Sethi et al., 1999).

Therefore, the purpose of this study is to detect the prevalence of Cryptosporidium sp. among malnourished children using conventional staining methods. 


\section{Materials and Methods}

The present study was conducted from May 2007 to Dec 2009, Stool samples (minimum 2 consecutive specimens) from malnourished children with and without diarrohea were collected from Meenakshi Medical College, Kanchipuram, Meenakshi Ammal Dental College and Hospital, Kanchi Kamakoti Child Trust Hospital and Udavum Karangal orphanage, Chennai.

Data were collected from each patient (after consent) regarding their age, sex, weigh, type of illness and clinical symptoms using questionnaires. Patients were categorized into 2 groups, one group suffering from acute diarrhoea (diarrhoea that begins recently and last for less than 14 days) and the other suffering from chronic diarrhoea (diarrhoea lasting longer than 2 weeks) (WHO 1992). Freshly voided fecal specimen was collected for coproparasitic and bacteriological study.

Examination for helminthes and protozoa in the stool samples were done by direct wet mount method and by formol-ether sedimentation method (Garcia and Bruckner, 1993). Smear made from the deposits were stained with modified Kinyoun acid fast stain (Ma and Soave, 1983) for Cryptosporidium (Fig. 1). Comparison of stained slide with positive slides for these coccidian parasites provided by the Centre for Disease Control and Prevention, Atlanta, Georgia, USA. Stool smear of Cryptosporidium positive cases were confirmed by the division of parasitic disease, CDC, Atlanta, Georgia, USA.

\section{Results and Discussion}

A total of 727 samples were examined out of which 497 were malnourished and 230 were normal. Of the 497 malnourished children, 397 had acute diarrhoea, 11 had chronic diarrhoea and 89 were control (without diarrhoea). Of the 230 normal children there were 135 acute diarrhoeal and 2 chronic diarrhoeal cases. 93 were control (without diarrhoea). Among these, cryptosporidial oocysts amounting to $12(2 \%)$ were detected only in the acute diarrhoeal cases of both malnourished and normal children. The Pearson chi square test was $=0.47, \mathrm{p}=0.50$ (not significant).

A total of 397 malnourished acute diarrhoeal cases $(54.6 \%)$ were included in the study. The age and sex-wise distribution depicted the prevalence of acute diarrhoeal infection in both sexes (male - 58, female - 43) predominantly in the range of 7-12 months of age $(25.44 \%)$. Of the 11 malnourished chronic diarrhoeal cases, 4male children fell in the age group of 7-12 months (36.36\%) and 3 female children in 49-96 months (27.27\%)

The age and sex-wise distribution of acute diarrhoeal cases in normal children were similar to that of malnourished children. Out of the total 135 cases, the predominant occurrence of acute diarrhoea was in 19 male children $(14.07 \%)$ who were in the age group of 7-12 months and 10 female children $(7.41 \%)$ in the age group of 49-96 months Age and sex-wise distribution of cryptosporidiosis associated diarrhea revealed a higher rate of incidence $6.38 \%$ in the age group of $25-48$ months out of which $2(7.14 \%)$ were male and $1(5.26 \%)$ were female children

In normal children with acute diarrhoea, the prevalence of cryptosporidial infection was found in 3.6\% in the age group of $0-6$ and $49-$ 96 months. Both the infections were found in male children. Of the 397 acute diarrhoeal cases studied $11.84 \%$ was positive for various intestinal parasites. The most common parasite encountered was Entamoeba sp. (32; 8.06\%) followed by Cryptosporidium sp. (10; 2.52\%), Giardia lamblia (3;0.76\%) and Ancylostoma duodenale and Ascaris lumbricoides (1; 0.25\% 
each). The detection rate of Entamoeba sp. was $18.18 \%$ among the 11 chronic diarrhoeal cases analyzed. Among the 89 age and sex matched control cases, 8 (8.99\%) were positive for intestinal parasites. The 8 cases comprised of 7 (7.87\%) Entamoeba sp. and 1 (1.12\%) Giardia lamblia. The details of parasites are depicted in Tables 1 and 2. There was no positivity for Cryptosporidium sp. for the chronic diarrhoeal and control cases.

In normal children Entamoeba sp. was the predominant parasite in acute $(13 ; 9.63 \%)$ and chronic $(2 ; 100 \%)$ diarrhoeal cases and cases without diarrhoea (control) (5; 5.38\%). Giardia lamblia was prevalent in $2(1.48 \%)$ acute diarrhoeal cases and $1(1.08 \%)$ control case. Two (1.48\%) acute diarrhoeal cases showed positivity for Cryptosporidium sp.

The prevalence of enteric bacterial pathogens among the malnourished and normal diarrhoeal cases were identified among which E. coli was predominant with 264 acute $(49.62 \%)$ and 6 chronic (46.15\%) diarrhoeal cases. No other bacterial pathogen was found in the chronic diarrhoeal cases. In acute diarrhoeal cases, E. coli was followed by 45 Vibrio cholerae (8.45\%), 13 Pseudomonas sp. (2.44\%), 13 Enterobacter sp. (2.44\%), 6 Shigella sp. (1.13\%), 5 Staphylococcus sp. (0.94\%), 4 Proteus sp. (0.75\%), 2 Salmonella sp. (0.38\%) and 1 Enterococci sp. (0.19\%), From the total 532 diarrhoeal cases analyzed, $12(2 \%)$ were positive for Cryptosporidium sp. in which $10(2 \%)$ were malnourished and 2 (1\%) were normal children. In the present study, Cryptosporidium sp. was identified as the predominant pathogen causing diarrhoea in 6 out of the 12 pathogens-positive specimens (50\%). Mixed infection of Cryptosporidium sp. with E. coli $(3 ; 25 \%)$, followed by Entamoeba sp. $(2 ; 16.67 \%)$ and Pseudomonas sp. (1; 8.33\%) was observed. During the period from May 2007 to Dec 2009 545, diarrhoeal samples (408 malnourished, 137 normal) were collected that were analyzed for the detection of cryptosporidial oocysts in acute diarrhoeal cases. In malnourished diarrhoeal children

Cryptosporidium sp. seemed to be prevalent mostly between October and December. But higher rate of incidence was observed in the months from July to September 2007 (14.71\%). In normal diarrhoeal children Cryptosporidium sp. prevailed from January to March 2007 (2.17\%) and from October to December 2008 (25\%).

Clinical history of the diarrhoeal patients was collected using a standardized proforma and the detailed clinical history of 12 Cryptosporidium-infected patients (malnourished and normal) was thoroughly analyzed. Among several clinical parameters studied, the discernible clinical features observed were watery diarrhoea $(100 \%$ in both cases), mild/moderate dehydration $(70 \%$ and $100 \%)$ and severe dehydration $(30 \%$, observed only in malnourished cases).

Two different frequencies of stool were observed 4 to 10 times a day $(90 \%$ and $50 \%)$ and $>10$ times $(10 \%$ and $50 \%)$. The other clinical features observed were fever $(70 \%$ and 50\%), weight loss (50\% and 100\%), abdominal pain (40\% and 100\%), nausea (50\% observed only in malnourished cases), vomiting ( $40 \%$ observed only in malnourished cases), anorexia (80\% and 50\%) and constipation (10\% observed only in malnourished cases). However there is no significant difference in clinical status among malnourished and normal children with diarrhoea assessed by Fisher's exact test and all are found to be insignificant (significant being $\mathrm{p}-0.05)$.

A total of 12 Cryptosporidium positives from acute diarrhoeal patients were analyzed semiquantitatively for the cryptosporidial oocyst in the faecal smears. 
Table.1 Frequency of Cryptosporidium sp. and other intestinal parasites encountered in malnourished children with and without diarrhoea

\begin{tabular}{|l|l|l|l|}
\hline Enteric parasites & $\begin{array}{l}\text { Acute diarrhoea } \\
(\mathbf{n = 3 9 7})\end{array}$ & $\begin{array}{l}\text { Chronic diarrhoea } \\
(\mathbf{n = 1 1})\end{array}$ & $\begin{array}{l}\text { Apparently } \\
\text { normal }(\mathbf{n}=89)\end{array}$ \\
\hline Entamoeba sp. & $32(8.06 \%)$ & $2(18.18 \%)$ & $7(7.87 \%)$ \\
\hline Cryptosporidium sp. & $10(2.52 \%)$ & 0 & 0 \\
\hline Giardia lamblia & $3(0.76 \%)$ & 0 & $1(1.12 \%)$ \\
\hline Ancylostoma duodenale & $1(0.25 \%)$ & 0 & 0 \\
\hline Ascaris lumbricoides & $1(0.25 \%)$ & 0 & 0 \\
\hline Negative & 350 & 9 & 81 \\
\hline
\end{tabular}

Table.2 Frequency of Cryptosporidium sp. and other enteric parasites in normal children with and without diarrhoea

\begin{tabular}{|l|l|l|l|}
\hline Enteric parasites & $\begin{array}{l}\text { Acute diarrhoea } \\
(\mathbf{n = 1 3 5 )}\end{array}$ & $\begin{array}{l}\text { Chronic } \\
\text { diarrhoea }(\mathbf{n}=\mathbf{2})\end{array}$ & $\begin{array}{l}\text { Apparently } \\
\text { normal (n=93) }\end{array}$ \\
\hline Entamoeba sp. & $13(9.63 \%)$ & $2(100 \%)$ & $5(5.38 \%)$ \\
\hline Giardia lamblia & $2(1.48 \%)$ & 0 & $\mathbf{1}(\mathbf{1 . 0 8 \% )}$ \\
\hline Cryptosporidium sp. & $2(1.48 \%)$ & 0 & 0 \\
\hline Ancylostoma duodenale & 0 & 0 & 0 \\
\hline Ascaris lumbricoides & 0 & 0 & 0 \\
\hline Negative & $\mathbf{1 1 8}$ & 0 & $\mathbf{8 7}$ \\
\hline
\end{tabular}

Fig.1 Modified Kinyoun's Acid-fast (cold) stain in a faecal smear (x100) showing spherical cryptosporidial acid-fast oocyst appears pink with pale centre of 4-6 $\mu \mathrm{m}$ in size

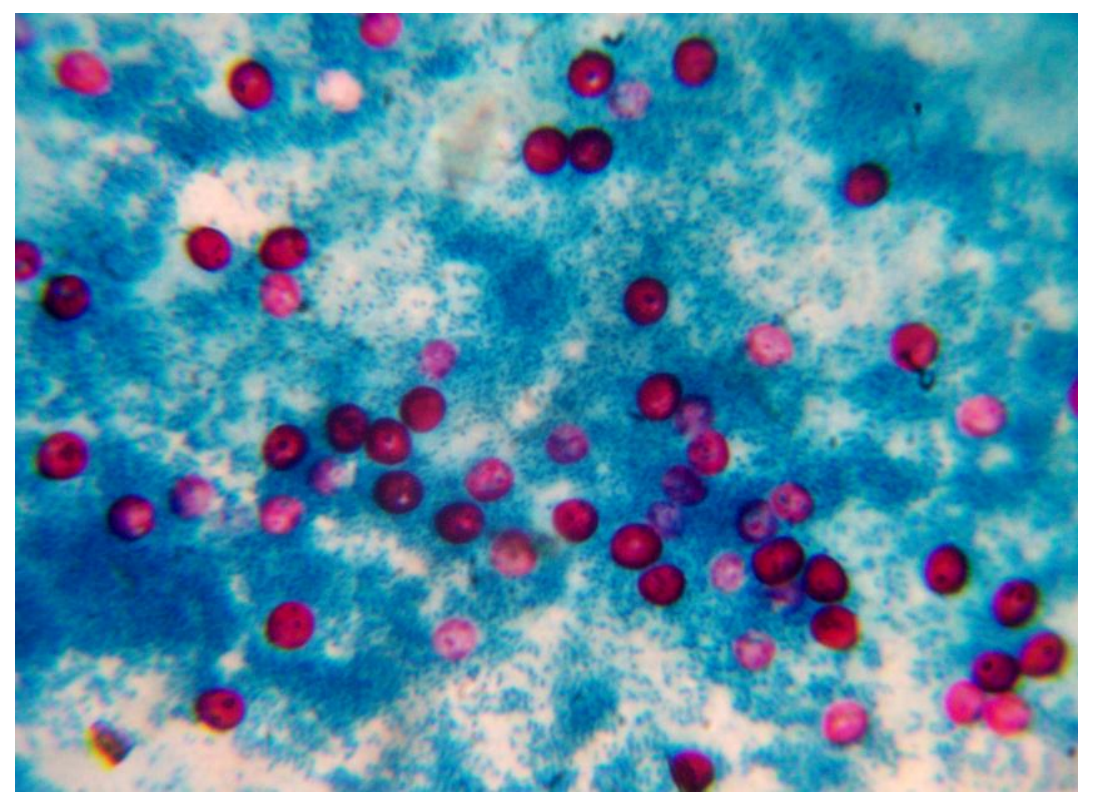


A major proportion of Cryptosporidiumpositive samples $(41.67 \%)$ exhibited about 610 oocysts in every field of search (x100). Four specimens contained more than 10 oocysts in every field and the rest were one oocyst in every 2-10 fields

Cryptosporidium sp. is regarded as causative agents of gastrointestinal illness characterized by diarrhoea in human beings especially in children. It is distributed worldwide since the first report of human cryptosporidiosis in 1976. Numerous reports of outbreaks have placed this parasite as an important enteric pathogen.

In the developing world, the association of Cryptosporidium sp. with acute and persistent diarrhoea in children is striking. In our study, children with cryptosporidiosis clinically presented with acute diarrhoea were similar to those seen with other enteric pathogens (Sallon et al., 1994). Both longitudinal studies from Brazil and Israel and those from GuineaBissau (Molbok et al., 1997) and Uganda (Tumwine et al., 2003) identified more persistent diarrhoea (lasting _14 days) than acute diarrhoea (lasting <4 days). However, no persistent diarrhoea was found in this study similar to the one from Vellore in southern India (Sitara et al., 2010). Several studies in children with diarrhoea suggest that the prevalence of cryptosporidiosis is endemic in developing countries. The rate of prevalence was found to be $28 \%$ in Ghana, $17 \%$ in Brazil and 26\% in Mexican (Newman et al., 1999, Andrew et al., 2004). In India, several studies in paediatric diarrhoea showed a prevalence rate of $1.3-13.1 \%$ from various parts of the country (Kammili et al., 2007). The present study shows that cryptosporidial infection is prevalent in $1.65 \%$ of children with acute diarrhoea which includes malnourished children (2\%) and normal children $(1 \%)$ which is similar to a study from Chandigarh (1.3\%) by Malla et al., (1987), another study from the same city $(1.4 \%)$ by (Sethi et al., 1999) and a study from Manipal (1.8\%) by (Shetty et al., 1995).

Generally Cryptosporidium sp. has been observed in persons from 3 days to 95 years of age, with young children being more susceptible to the infection. In our study, male children are more vulnerable to the infection (7/12) than female children (5/12). Cryptosporidiosis is predominant in malnourished (Malathi Murugesan et al., 2017), especially in male children in the age group of 25-48 months (7.14\%) than female children in the age group of 13-24 months $(10 \%)$. Children in the age group of 24 to 48 months were found to be most vulnerable to infection as observed among children in Kuwait (Sulaiman et al., 2005). However, infections did not vary much with sex in our study similar to the study conducted by (Gatei et al., 2006) among Kenyan children.

No prevalence of Cryptosporidium sp. was found in normal healthy children with and without diarrhoea which does not agree with the study from Tunisia where, the prevalence of Cryptosporidium sp. in healthy children was $1.7 \%$ and $9.8 \%$ from southern India (Mathan et al., 1985; Essid et al., 2008). In the present study, Cryptosporidium sp. ranks second in malnourished and third in normal diarrhoeal children. The predominant parasite found in both groups was Entamoeba sp. $(8.3 \%)$ whose prevalence was higher than the studies from Chandigarh, Saudi Arabia and Bangalore (1-6.8\%) studied by (Sethi et al., 2000, Al-Eissa et al., 1995) and Chavalittamrong and Jirapinyo (1984). Other parasites such as Giardia lamblia, Ancylostoma duodenale and Ascaris lumbricoides were also seen in our study.

A total of 545 enteric bacterial pathogens were isolated from malnourished and normal children with diarrhoea. The most common 
bacterial pathogen causing diarrhoea (predominantly acute) was found to be E. coli. The present study correlates with a rural coherent study from Karnataka conducted Mamatha (2005). The most common enteric pathogens involved in co-infection with Cryptosporidium-infected Kenyan children were Entamoeba sp. (6\%), E. coli (5\%) and Giardia intestinalis (2\%) (Gatei et al., 2006). Of the 12 Cryptosporidium-positive cases in our study, 6 were associated with other enteric pathogens which include $E$. coli (25\%), Entamoeba sp. (16.67\%) and Pseudomonas sp. (8.33\%).

The clinical proforma of 12 Cryptosporidiuminfected patients (malnourished and normal) was thoroughly analyzed. Among several clinical parameters studied, the discernible clinical features observed were watery diarrhoea $(100 \%$ in both cases), mild/moderate dehydration $(70 \%$ and $100 \%)$ and severe dehydration $(30 \%$, observed only in malnourished cases). Two different frequencies of stools were observed -4 to 10 times a day (90\% and 50\%) and >10 times $(10 \%$ and $50 \%)$. The other clinical features observed were fever (70\% and $50 \%)$, weight loss $(50 \%$ and $100 \%)$, abdominal pain $(40 \%$ and $100 \%$ ), nausea (50\% observed only in malnourished cases), vomiting (40\% observed only in malnourished cases), anorexia (80\% and $50 \%)$ and constipation (10\% observed only in malnourished cases). In a study by (Andrew et al., 2004) from 227 children with diarrhoea, the clinical presentation observed was abdominal pain (37\%), nausea (47.6\%), vomiting (42.9\%) and blood in stool (25\%).

The analysis of clinical symptoms of patients with cryptosporidiosis may thus help in the prognosis of the infective patients, thereby assisting in the early diagnosis of the disease and also prevents unwanted antibiotic therapy. In tropical countries, prevalence of cryptosporidiosis is highest in rainy season.
This could be due to contamination in surface water in catchments areas following rains (Kammili et al., 2007). Moreover cryptosporidial oocysts are sensitive to heat and resistant to chlorine. Viable oocysts are likely to be present in more numbers in water during rainy season. Similarly in the present study, cryptosporidiosis was found to be a seasonal disease. Highest number of occurrences was found clustered in the months of July, August, September, and December when rainfall used to be very heavy. Similar observations were made in Brazil and Indonesia (Newmann et al., 1999; Katsumata et al., 1998) and were also seen in a study from Delhi (Ravinder et al., 2002).

In the present study, cryptosporidiosis seemed to be more common in malnourished children in developing countries than well nourished normal children with diarrhoea in our present study. The Cryptosporidium-stool positive children were significantly malnourished than those in whom the infection was not detected. The observation of the present study corroborated with a similar study conducted by (Sallon et al., 1988) in malnourished children hospitalized with diarrhoea. The present study highlights the importance of proper nutrition to children as it plays a vital role in reducing the vulnerability of children from acquiring cryptosporidial infection.

\section{Acknowledgement}

I would be remiss if I didn't especially thank Dr. Stephanie P Johnston, M.S., Microbiologist, Reference and Diagnostic Laboratory, Division of Parasitic Disease, CDC, Atlanta, USA, for confirming the faecal smears.

\section{References}

Al-Eissa YA, Assuhaimi SA, Abdullah AMA, et al., (1995). Prevalence of intestinal 
parasites in Saudi children: a community based study. J Trop Pediatr 41: 47-9.

Andrew AA, Henry A, Lornna R, Patient B, Sifah E, et al., (2004). Cryptosporidium Spp. a frequent cause of diarrheae among children at the Korle - Buteaching Hospital, Accra Ghana. Jpn. J. Infect. Dis., 57, 216-219, 2007.

Chavalittamrong B, Jirapinyo P. (1984). Intestinal parasites in pediatric patients with diarrhoeal diseases in Bangkok. Southeast Asian J Trop Med Public Health 15: 385-8.

Current WL and LS Garcia (1991). Cryptosporidiosis. Clin Microbiol Rev 4: 325-58.

Essid R, Mousli M, Aoun K, Abdelmalek R, Mellouli F, Kanoun F, Derouin F and Bouratbine A, 2008. Identification of Cryptosporidium species infecting humans in Tunisia. Am J Trop Med Hyg 79: 702-5.

Garcia, L.S and Bruckner, D.A. (1993): Macroscopic and microscopic examination of fecal specimens.p.508 512. In L.S. Garcia (ed), Diagnostic Medical Parasitology. $2^{\text {nd }}$ Am Soc Micro, Washinton D.C.

Gatei W, Wamae CN, Mbae C, Waruru A, Muline E, Waithera T, Gatika SM, Revathi G, Hart CA (2006). Cryptosporidiosis: prevalence, genotype analysis and symptoms associated with infections in children in Kenya. Am $J$ Trop Med Hyg 75: 78-82.

Hunter PR, Nichols G (2002). Epidemiology and clinical features of Cryptosporidium infection in immunocompromised patients. Clin Microbiol Rev 15: 145-54 [abstract].

Kammili N, Pavuluri PRR, Gyaneswari M, Prasanthi K, Rao IDS, Saxena NK (2007). Molecular characterization of Cryptosporidium an emerging parasite. Indian J Med Microbiol 25: 133-6.
Katsumata T, Hosea D, Wasito EB, Kohno S, Soeparto P, Ranuh IG (1998). Cryptosporidiosis in Indonesia: A hospital based study and a community based survey. Am J Trop Med Hyg 59: 628-32.

Ma P. Soave R. (1983). Three- step stool examination for Cryptosporidiosis in 10 homosexual men with protracted watery diarrhoea. J Infect Dis.; 147: 824 - 8.

Malathi Murugesan, Santhosh Kumar Ganesan, and Sitara SR Ajjampur (2017). Cryptosporidiosis in children in the Indian subcontinent. Trop Parasitol. 2017 Jan-Jun; 7(1): 18-28.d

Malla N, Sehgal R, Ganguly NK, Mahajan RC (1987). Cryptosporidiosis in children in Chandigarh. Indian $\mathrm{J} \mathrm{Med}$ Res 86: 722-5.

Mamatha B and Ramamurthy T (2005). Enteroaggregative Escherichia coli diarrheoa in Manipal. Ind Ped 42: 7223.

Mathan MM, Venkatesan S, George R, Mathew M, Mathan VI (1985). Cryptosporidium and diarrhoea in southern India children. Lancet 2: 11725.

Molbak K, Andersen M, Aaby P, Hojlyng N, Jakobsen M, Sodemann M, da Silva Ap (1997). Cryptosporidium infection in infancy as a cause of malnutrition: a community study from Guinea-Bissau, west Africa. Am J Clin Nutr 65: 149-52.

Newman RD, Sears CL, Moore SR, Nataro JP, Wuhib T, Agnew DA, et al., (1999). Longitudinal study of Cryptosporidium infection in children in northeastern Brazil. J Infect Dis 180: 167-75.

Ravinder K, Deepti R, Manish K, Beena U and Sharma VK (2002). Intestinal parasites in children with diarrhoea in Delhi, India. Southeast Asian J Trop Med Pub Health 33: 725-9. 
Reading on diarrhoea: student manual. Geneva: World Health Organization; (1992), p 4-5.

Sallon S, el-Shawwa R, Khalik M, et al., (1994). Diarrhoeal disease in children in Gaza. Ann Trop Med Parasitol 88: 17582.

Sallon S, Richard DJ, Irmgard IS, Susan H, Mario B, Dan TS (1988). Cryptosporidium, Malnutrition, and Chronic Diarrhoea in Children. Am J Dis Child 142: 312-5.

Sethi S, Sehgal R, Malla N, Dubey ML, Mahajan RC (2000). Changing trends of intestinal parasitic infections in Chandigarh (northern India): hospitalbased study. Ind J Med Microbiol 18: 106-9.

Sethi S, Sehgal R, Malla N, Mahajan RC (1999). Cryptosporidiosis in a tertiary care hospital. Natl Med J India 12: 207 9.
Shettty M, Brown TA, Kotian M, Shivananda PG (1995). Viral diarrhoea in a rural coastal region of Karnataka India. Trop Pediatr 41: 301-3.

Sitara SRA, Rajiv S, Premi S, Arun K, Vipin KM, Jayaprakash M, Honorine $\mathrm{W}$ and Gagandeep K (2010). Symptomatic and asymptomatic Cryptosporidium infections in children in a semi-urban slum community in southern India. Am J Trop Med Hyg 83: 1110-5.

Subramanyam VR, Broadhead RL, Pal BB, Pati JB, Mohanty G (1989). Cryptosporidiosis in children of eastern India. Ann Trop Paediatr 9: 122-5.

Tumwine JK, Kekitiinwa A, Nabukeera N, et al., (2003). Cryptosporidium parvum in children with diarrhoea in Mulago Hospital, Kampala, Uganda. Am J Trop Med Hyg 68: 710-5.

\section{How to cite this article:}

Chamundeeswari, G.S., R. Raghuraman and Raman, M. 2018. Detection of Cryptosporidium species among Malnourished Children in and around Chennai, Tamil Nadu, Southern India. Int.J.Curr.Microbiol.App.Sci. 7(04): 2924-2931. doi: https://doi.org/10.20546/ijcmas.2018.704.333 